\title{
PERFORMANCE OF MESOPHYTIC SPECIES PLANTED IN THE COAST OF CHAR KASHEM, PATUAKHALI, BANGLADESH
}

\author{
Mo Golam Moula \\ Bangladesh Forest Research Institute, Post Box No. 273, Chittagong 4000, Bangladesh \\ Key words: Mesophytes, Coastal afforestation, Growth performance, Bangladesh
}

\begin{abstract}
Mesophytic species such as Acacia nilotica, Albizia labeck, Albizia procera, Casuarina equisetifolia, Pithocellobium dulche, Samanea saman and Thespesia populnea were raised in the western coast of Char Kashem under Patuakhali district of Bangladesh. After seven years of planting highest survivability was found in A. labeck followed by P. dulche, C. equisetifolia, S. saman, A. procera, A. nilotica and T. populnea. The mean maximum diameter at breast height was found in $S$. saman followed by C. equisetifolia, A. procera, A. labeck, $P$. dulche, A. nilotica and T. populnea. The maximum plant height was found in $C$. equisetifolia followed by S. saman, A. procera, T. populnea, A. nilotica, A. labeck and $P$. dulche indicating suitability of all the seven species for plantation at Char Kashem.
\end{abstract}

Coastal afforestation in 1966 was primarily initiated to save lives and properties of the coastal dwellers from the devastating cyclones and tidal surges (Das and Siddiqi 1985) and secondarily to (i) reclamation and stabilization of newly accreted land and acceleration of further accretion, (ii) production of timber and fuel wood and (iii) creation of employment opportunity in the coastal areas (Saenger 1987). The coastal afforestation programme gained a momentum with the involvement of World Bank in 1975 (Imam 1982). Up to 2001 a total of 1,48,526 hectares of mangrove plantation has been established under different projects. Now the total plantation area stands as 1,70,000 hectare (Aziz 2010). Sonneratia apetala and Avicennia officinalis proved to be most successful species by their higher survival and growth performance (Siddiqi et al. 1992).

The coastal ecosystem is a highly dynamic ecosystem (Serajuddoula et al. 1995). Due to lack of regular inundation, the raised area lost the suitability for growth and yield of mangrove species and thus it is necessary to cover these vacant areas by non-mangrove (mesophytic) species (Imam 1982). Therefore on the basis of preliminary observation a study was undertaken to find out the suitability of seven mesophytic species Acacia nilotica, Albizia labeck, Albizia procera, Casuarina equisetifolia, Pithocellobium dulche, Samanea saman and Thespesia populnea in the western coast belt of Char Kashem, Rangabali Police Station under Patuakhali district of Bangladesh in 1998 (Table 1). The experiment was laid out in the raised areas of the western coastal belt at Char Kashem, under Patuakhali district of Bangladesh. Soil characteristic are mentioned elsewhere (Hasan 1987, Chowdhury and Chowdhury 1994, Karim 1994, Khan et al. 1998).

Table 1. Vernacular name, scientific name and family name of the species tried.

\begin{tabular}{llll}
\hline Treatments & Vernacular name & Scientific name & Family \\
\hline T1 & Raintree & Samanea saman & Fabaceae \\
T2 & Shown balai & Thespesia populnea & Malvaceae \\
T3 & Khair & Pithocellobium dulche & Fabaceae \\
T4 & Sada Karai & Albizia procera & Fabaceae \\
T5 & Jhaw & Casuarina equisetifolia & Casuarinaceae \\
T6 & Babla & Acacia nilotica & Fabaceae \\
T7 & Kala Karai & Albizia labeck & Fabaceae \\
\hline
\end{tabular}

$\overline{\text { E-mail: gmoulabfri@yahoo.com }}$ 
The seeds/fruits were collected from phenotypically superior tree from January to April and sown in polybags of $15 \mathrm{~cm} \times 23 \mathrm{~cm}$ filled with powdered loamy soil and cowdung at $3: 1$ ratio. Seedlings were raised in a nursery bed and were kept for six month under shed and one month exposed.

The experimental site was prepared by jungle cutting, burning and removing debris. Heaps of size $60.96 \mathrm{~cm} \times 60.96 \mathrm{~cm} \times 60.96 \mathrm{~cm}$ were prepared and the experimental plots were fenced with barbed wire to protect the plants from biotic interference.

In each plots $49(7 \times 7)$ seedlings were planted at $2.13 \mathrm{~m} \times 2.13 \mathrm{~m}$ spacing. Seven plots were made in each block and each block is considered as a replicate. The experiment was laid out in Randomized Complete Block Design (RCBD) with seven treatments and three replications. The experimental lay out is shown in Table 2 .

Table 2. Experimental layout.

\begin{tabular}{lccccccc}
\hline $\begin{array}{l}\text { Plot/ } \\
\text { block }\end{array}$ & $\begin{array}{c}\text { Plot } \\
\text { no. } 1\end{array}$ & $\begin{array}{c}\text { Plot } \\
\text { no. 2 }\end{array}$ & $\begin{array}{c}\text { Plot } \\
\text { no. 3 }\end{array}$ & $\begin{array}{c}\text { Plot } \\
\text { no. 4 }\end{array}$ & $\begin{array}{c}\text { Plot } \\
\text { no. 5 }\end{array}$ & $\begin{array}{c}\text { Plot } \\
\text { no. 6 }\end{array}$ & $\begin{array}{c}\text { Plot } \\
\text { no. 7 }\end{array}$ \\
\hline Block-1 & T3 & T5 & T2 & T6 & T1 & T7 & T4 \\
Block-2 & T6 & T4 & T7 & T3 & T5 & T2 & T1 \\
Block-3 & T7 & T1 & T5 & T2 & T6 & T4 & T3 \\
\hline
\end{tabular}

Data on survival, diameter and height growth were collected in June and December of a year for about 6 years. The final data were collected in June 2005 and statistically analyzed. The mean highest survivability (as \%) was found in A. labeck (97.96) followed by P. dulche (97.28), C. equisetifolia (96.60), S. saman (90.48), A. procera (88.24), A. nilotica (82.99) and T. populnea (80.27), shown in Table 3.

Table 3. Mean survivability (\%), diameter $(\mathrm{cm})$ and height $(\mathrm{m})$ of seven mesophytic species after seven years of planting. $n=3$, mean \pm standard deviation.

\begin{tabular}{lllcl}
\hline Treatments & Taxa & $\begin{array}{c}\text { Survivability } \\
(\%)\end{array}$ & $\begin{array}{c}\text { Diameter growth } \\
(\mathrm{cm})\end{array}$ & $\begin{array}{c}\text { Height growth } \\
(\mathrm{m})\end{array}$ \\
\hline T1 & Samanea saman & $90.48 \pm 8.25$ & $13.17 \pm 1.76$ & $10.70 \pm 1.18$ \\
T2 & Thespesia populnea & $80.27 \pm 6.56$ & $7.39 \pm 0.66$ & $8.07 \pm 2.38$ \\
T3 & Pithocellobium dulche & $97.28 \pm 3.12$ & $7.89 \pm 1.22$ & $6.40 \pm 0.63$ \\
T4 & Albizia procera & $88.44 \pm 6.24$ & $11.24 \pm 1.17$ & $10.65 \pm 2.26$ \\
T5 & Casuarina equisetifolia & $96.60 \pm 3.12$ & $12.15 \pm 1.22$ & $13.17 \pm 0.76$ \\
T6 & Acacia nilotica & $82.99 \pm 14.77$ & $7.57 \pm 0.10$ & $7.47 \pm 0.76$ \\
T7 & Albizia labeck & $97.96 \pm 00.00$ & $9.56 \pm 0.70$ & $7.42 \pm 1.26$ \\
\hline
\end{tabular}

The mean maximum diameter (in $\mathrm{cm}$ ) at breast height (DBH, $1.30 \mathrm{~m}$ ) was found in $\mathrm{S}$. saman (13.17) followed by C. equisetifolia (12.15), A. procera (11.24), A. labeck (9.56), P. dulche (7.89), A. nilotica (7.57) and T. populnea (7.39), shown in Table 3.

The mean maximum height (in $\mathrm{m}$ ) was found in C. equisetifolia (13.17) followed by $S$. saman (10.70), A. procera (10.65), T. populnea (8.07), A. nilotica (7.47), A. labeck (7.42) and P. dulche (6.40 m), shown in Table 3.

Siddiqi et al. (1994) found the S. saman, A. procera, A. nilotica, and Lagerstroemia speciosa (Jarul) as promising for large scale plantation in raised Non-Commercial Cover (NCC) areas of the Sundarbans. According to Serajuddoula et al. (1995) C. equisetifolia and A nilotica are the most promising species followed by S. saman, A. procera, T. populnea and $P$. dulche after four years of 
planting at Rangabali under Patuakhali District. At Char Kukri-mukri under Bhola District A. nilotica, S. saman, P. dulche, A. labeck, D. sisso and Syzygium cumini (Jam) showed the best performance (Serajuddoula et al. 1995).

The plantation of mesophytic species in the coastal areas is likely to offer sustained yield and render a permanent forest cover in the coastal belt. On the basis of survival and growth performance all these seven species were found promising for plantation in the accreted land at Char Kashem under Patuakhali District.

\section{Acknowledgement}

The author is grateful to the authority of Bangladesh Forest Research Institute for giving opportunity to conduct the present study.

\section{References}

Aziz A 2010. Coastal and marine plant resources of Bangladesh: management and exploitation. Keynote paper, Annual Bot. Conf., Univ. Chittagong, Chittagong.

Chowdhury AB and A Chowdhury 1994. Mangrove of the Sundarbans. Volume one: India. IUCN, Bangkok. $247 \mathrm{pp}$.

Das S and NA Siddiqi 1985. The Mangrove and Mangrove Forest of Bangladesh. Mangrove Silviculture Division. Bull. No. 2. Banglaesh Forest Research Institute. Chittagong.

Hasam MN 1987. Preliminary report on coastal afforestation sites. In: The maturing mangrove plantations of the coastal Afforestation Project. Drigo et al. (Eds), pp. 64-66. Field Document No. 2. FAO/UNDP project BGD/85/085.

Imam SA 1982. Sundarbans and its future. Proc. of the Second National Conf. on Forestry. Jan. 21-26. Forest Department. Dhaka. pp. 19-24.

Karim A 1994. The physical Environment. In: Mangrove of the Sundarbans. Volume two Bangladesh. Hussain Z and G Acharya (Eds), pp.11-42. IUCN, Bangkok.

Khan Z, HMS Husain and AR Mazumder 1998. Properties of soils from the offshore islands of Bangladesh. Bangladesh J. Forest Sci. 27(2): 114-120.

Saenger P 1987. Bangladesh Mangrove Afforestation Project Shedden Pacific Pvt. Ltd., Melbourne. 62 pp.

Serajuddoula M, MAS Khan, MR Islam and MAH Shahjalal 1995. Inroduction of non-mangrove in raised coastal land - A way to maintain sustainable forest in coastal belt of Bangladesh. Pakistan J. Forestry. 45(4): 163-169.

Siddiqi NA, MAS Khan, MR Islam and AKF Hoque 1992. Underplanting- a means to ensure sustainable mangrove plantations in Bangladesh. Bangladesh J. Forest Sci. 21(1-2): 1-6

Siddiqi NA, M Shahidullah and MAH Shahjalal 1994. Studies on mesophytic and mangrove species in the poorly regenerated areas of the Sundarbans. Bull. 3. Mangrove Series. Bangladesh Forest Research Institute, Chittagong. $31 \mathrm{pp}$.

(Manuscript received on 27 April, 2010; revised on 19 August, 2010) 